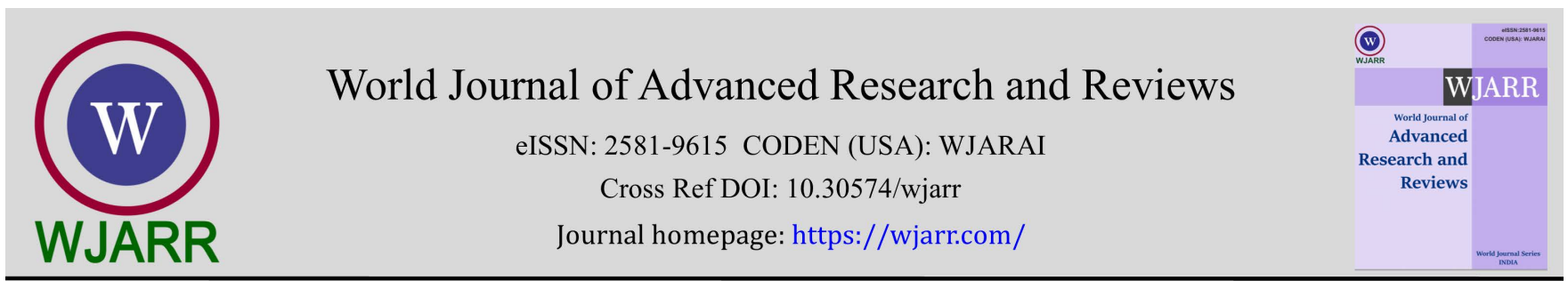

(RESEARCH ARTICLE)

\title{
Prevalence of Staphylococcus aureus and Candida albicans coinfections amongst university community in southwest Nigeria
}

\author{
BA Erinle $1,{ }^{*}$, TT Adebolu ${ }^{1}$ and AO Ajayi ${ }^{2}$ \\ ${ }^{1}$ Microbiology Department, Federal University of Technology, Akure, Nigeria. \\ 2 Microbiology Department, Adekunle Ajasin university, Akungba, Nigeria.
}

World Journal of Advanced Research and Reviews, 2022, 18(02), 511-515

Publication history: Received on 12 January 2022; revised on 18 February 2022; accepted on 20 February 2022

Article DOI: https://doi.org/10.30574/wjarr.2022.13.2.0162

\begin{abstract}
Background: Staphylococcus aureus is a bacterium that is common and frequent polymicrobial pathogen. It constitutes a global burden to human health. Similar characteristic features displayed by Candida albicans also causes fungal infections. The interaction generally of the coinfections exhibited is of greater magnitude on these duo microbes at teaching hospitals and big clinical facilities but the extent in the convectional university is what we cannot really ascertain and this the basis for which the study is done.
\end{abstract}

Method: We examined the prevalence of Staphylococcus aureus and Candida albicans on mid steam urine, swabbed wound and high vaginal swabs. Samples were obtained from 520 patients between March 2019 to May 2020 from students and staff of the Federal university of Technology, Akure. Aged 1 to 69 years that visited the medical centre based on complaints and symptoms presented. Laboratory analysis was conducted, the samples were processed, identified microscopically, culturally and biochemically using standard procedures.

Result: The prevalence of Candida albicans and Staphylococcus aureus coinfection was 2.9\% (15) of the 520 participants. Out of which 252 (48.4\%) were male and 268 (51.6\%) were female. The highest prevalence of 35.8\% was observed among the age group (11-20) years.

Conclusion: The prevalence of Candida albicans coinfection with Staphylococcus aureus is low. The study established it foray in university community. However, initiating prevention strategy with more studies and knowledge of their interactions open a new path to circumvent the prevalence in the next research study.

Keywords: Prevalence; Staphylococcus aureus; Candida albicans; Coinfection

\section{Introduction}

Among the vast number of human pathogens, the bacterial species Staphylococcus aureus and the fungal species are currently the second and third most commonly isolated bloodstream pathogens [1, 2]. In particular attention Staphylococcus aureus has gained considerable attention from the medical community due to its involvement in the increasing number of nosocomial and acquired infection resulting in nearly half a million hospitalization and 50,000 death each year in the USA alone [1,3]. This bacterial species is armed with an array of virulence factors including toxin and immunoavoidance strategies for invading and destroying host tissue during infection. [4, 5] despite its pathogenic potentials Staphylococcus aureus is typically a noninvasive commensal and has been historically identified as a common nasopharyngeal resident but is also found localized associated with moist skin areas of the axillae and groin. However, the microbial species has more recently been found to commonly exist in the oral cavity. Staphylococcus aureus typically

\footnotetext{
* Corresponding author: BA Erinle

Microbiology Department, Federal university of Technology Akure, Nigeria.
}

Copyright $(2022$ Author(s) retain the copyright of this article. This article is published under the terms of the Creative Commons Attribution Liscense 4.0. 
requires a breech. In mucosal barriers to gain entry into the epithelium during infection [6], S. aureus produces numerous enzymes such as proteases, lipases, and elastases that enable it to invade and destroy host tissues and metastasize to other sites. $S$. aureus is also capable of producing septic shock. It does this by interacting with and activating the host immune system and coagulation pathways $[7,8,9]$ Staphylococcus aureus has numerous mechanisms to produce disease and to evade host defences, however it is important to note that not all S. aureus are created equal, different strains may contains different adhesions or toxin or may differ in their ability to produce biofilms and resist phagocytes [10].

Similarly, Candida albicans is the most frequently encountered pathogenic human fungal species and commonly colonizes host mucosal and moist skin surfaces [11] Candida albicans colonizes the oral cavity, vagina and gastrointestinal tract in most humans [12]. It is however also an opportunistic pathogen, able to cause both superficial and systemic infections, the latter mainly in immunocompromised patients. In certain niches of the host, $C$. albicans coexists with commensal bacteria, including Staphylococcus species [13]. A vast number of infections including those of Candida albicans and Staphylococcus species originate from biofilms and they are often associated with high mortality rates [13] C. albicans and Staphylococcal species were co -isolated from various biofilm associated diseases, including urinary tract, burns, wound infections, denture stomatitis and infections of medical devices such as central nervous catheters $[14,15]$. The complexity of these polymicrobial infections poses an additional challenge to find efficient treatment strategies [16]. Approximately $75 \%$ of all women experience at least one episode of vaginal candidiasis and $40-50 \%$ will have recurrent episodes in their life time $[17,18]$.

\section{Material and methods}

Study population. In this study a cross sectional design was conducted between March 2019 to May 2020 . A total of 520 samples comprising 252 male and 268 female of students, staff and their dependents in the Federal university of Technology Akure Nigeria. Aged 1 to 69 years with complaints and symptoms from the subjects were presented at the university Medical Center.

Laboratory Diagnosis; Sterile universal bottles, sterile swab sticks were used to void mid steam urine, swabbed wound and vaginal swabs were collected from the subjects. Without delay the samples were assayed. Samples cultured on Mannitol salt agar (MSA), MacConkey Agar, Blood agar in the case of urine and wound swab and Sabouraud dextrose agar (SDA) for vaginal swab. The agar plates were incubated in an incubator at $37^{\circ} \mathrm{C}$ for 24 hrs while SDA incubated at $35^{\circ} \mathrm{C}$ after $24 \mathrm{hrs}$ incubation. Pure culture were obtained by streaking colony on Nutrient agar and SDA until single colonies were obtained after incubation. All tests were performed using the method of Cheesebrough, 2006 [19]. Wet preparation of the vaginal swabs was made with $10 \%$ potassium hydroxide. The growth and colony color examined and identification test performed viz a viz; gram stain, coagulase test, and catalase test for Staphylococcus aureus using standard procedures. Germ tube test in serum was used to identify Candida albicans at $37^{\circ} \mathrm{C}$

\section{Results}

Table 1 Age range data distribution

\begin{tabular}{|l|l|l|l|}
\hline Age & No of samples & Percentage (\%) & $\begin{array}{l}\text { S. aureus } \\
\text { Candida albicans }\end{array}$ \\
\hline $0-10$ & 24 & 4.6 & - \\
\hline $11-20$ & 186 & 35.8 & 6 \\
\hline $21-30$ & 164 & 31.5 & 4 \\
\hline $31-40$ & 75 & 14.4 & 3 \\
\hline $41-50$ & 40 & 7.7 & 2 \\
\hline $51-60$ & 22 & 4.2 & - \\
\hline $61-69$ & 9 & 1.8 & - \\
\hline Total & 520 & 100 & 15 \\
\hline
\end{tabular}


During the study period 520 samples were analyzed from the patients with signs and symptoms i.e. itching, vagina discharge and pain in urination. Of them 15(2.79\%) had Candida albicans coinfections Staphylococcus aureus. 252 (48.4\%) were male and 268 (51.6\%) were female. The highest prevalence of $35.8 \%$ was observed among age group (11 -20) followed by $21-30$ (31.5\%) and $31-40$ (14.4\%) as indicated in Table 1. The sex distribution by Male is illustrated in Table 2 with age group 11 -20 years had highest prevalence.

Table 2 Sex Date Distribution (Male)

\begin{tabular}{|l|c|c|c|c|}
\hline Age & Number of samples & Percentage (\%) & Staphylococcus aureus (\%) & Candida albicans (\%) \\
\hline $0-10$ & 13 & 5.1 & 2 & - \\
\hline $11-20$ & 88 & 35.0 & 8 & 2 \\
\hline $21-30$ & 80 & 31.8 & 4 & 1 \\
\hline $31-40$ & 35 & 13.8 & 3 & 1 \\
\hline $41-50$ & 19 & 7.6 & 2 & - \\
\hline $51-60$ & 10 & 4.0 & 2 & - \\
\hline $61-69$ & 7 & 2.7 & - & 4 \\
\hline Total & 252 & 100 & 21 & - \\
\hline
\end{tabular}

Table 3 Sex Data Distribution (Female)

\begin{tabular}{|c|c|c|c|c|}
\hline Age & Number of samples & Percentage (\%) & Staphylococcus aureus & Candida albicans \\
\hline $0-10$ & 11 & 4.1 & 1 & - \\
\hline $11-20$ & 98 & 36.6 & 10 & 11 \\
\hline $21-30$ & 84 & 31.3 & 7 & 7 \\
\hline $31-40$ & 40 & 15.0 & 5 & 3 \\
\hline $41-50$ & 21 & 7.9 & 4 & 2 \\
\hline $51-60$ & 12 & 4.4 & 2 & 2 \\
\hline $61-69$ & 2 & 0.7 & - & 25 \\
\hline Total & 268 & 100 & 29 & \\
\hline
\end{tabular}

\section{Discussion}

Candida albicans and Staphylococcus aureus had been isolated from several clinical specimens from different part of Nigeria [20] and different part of the world [21,22]. The current study therefore, study the prevalence of Candida albicans and Staphylococcus aureus coinfection in the convectional university which is low according to the study is $2.9 \%$. This is in tandem with other researchers that it varies from 1 to $10 \%$ prevalence of Candida coinfection. Notable country around the world that this statement collaborates with was reported by China [23] (2.2\%) Tunisia [24] and United States of America (USA) [25] what reason could be attributed to this? It could be multifactorial ranging from immune status of the patients, hormonal influences, and hygiene and socio- demographic characteristics. Although data on the clinical relevance of bacteria-fungi interactions are limited, several studies have described the association of bacteria and Candida species in a range of clinical specimens which varies between countries, depending on the country, region and populations $[28,29,30]$. This study conformed with the findings according to Adad et al., 2001 and Alli et al., $2011[26,27]$ that infections by Candida species were most frequent among younger patients especially those ages under 20 years. Table 2 and Table 3 attested to it. 35\% of the Male (88/252) were in the age bracket of 11 - 20 years. So also, in Table 3 where $36.6 \%$ of the female participants (98/268). Even the Staphylococcus aureus isolated were more in that age group although more female were infected with Candida albicans than the male as shown in the tables. 


\section{Conclusion}

The study revealed low rate of Candida albicans coinfection with Staphylococcus aureus in a convectional university community, especially amongst young youth that are prone and vulnerable to infection due to youthful exuberance and sexual behaviors. Intensify good hygiene, environmental sanitation and in-depth insights on their interactions is a novel step to open up further study.

\section{Compliance with ethical standards}

\section{Acknowledgments}

I wish to thank all the member of staff of the university, and Medical Centre for the cooperation and support in handling and collection of clinical samples for the study.

\section{Funding}

I want to thank the President of the university cooperative society for granting me access to loan for the purpose of the research study. It was timely and met my need for the project.

\section{Disclosure of conflict of interest}

The authors declare that they have no competing interests.

\section{Statement of informed consent}

Informed consent was obtained from all individual participants included in the study.

\section{References}

[1] Goetghebeur M, Pierre -Alexandre L, Colin V. Methincillin-resistant Staphylococcus aureus. A public health issue with economic consequences. Canadian Journal of Infectious disease and Medical Microbiology. 2007; 18(1).

[2] Klevens RM, Edwards JR, Richard CL. Estimating health care associated infections Public Health Reports. 2007; 122: 160 -166.

[3] Gordon RJ, Lewy FD. Pathogenesis of methicillin resistant Staphylococcus aureus Clin, infect.Dis. 2008; 5: S350 S359.

[4] Bein J. Sokolova GO, Bozko P. Characterization of virulence infections of Staphylococcus aureus. Novel function of knowPan virulence factors that are implicated in activation of airway epithelial pro inflammatory response thogen. $2011 ; 60 ; 190-195$.

[5] Ferry T, Thomas P, Francois V, Jerome E. Virulence determinants in Staphylococcus aureus and their involvement in clinical syndromes. 2005. Current Infectious Disease Reports 7 Article 420.

[6] Acton DS, Plat-Siminiye MJ, Vanwarrel W, Decrant N, Van- Belkum, A. 2009.Intestinal carriage of Staphylococcus aureus how does it frequency compare with that of nasal carriage and what is its clinical impart. Eur, J . Clin. Microbiol.lnfect. Dis. $28: 115-127$.

[7] Timmerman CP, Mattson E, Martinez -Martinez L .Induction of release of tumor necrotic factor from human monocytes of Staphylococci and Staphylococcal peptidoglycan. Infect.lmmun. 1993; 61: 4127 -72.

[8] Heumann D, Barrasi C, Severin A, Glauser MP, Tomasz A. Gram positive cell walls stimulate synthesis of tumor necrosis factor Alpha and interleukin 6 by human monocytes Infect. 1994; 62: 2715 -21.

[9] Bhakdi S, Tranum- Jensen J. Alpha toxin of Staphylococcus aureus. Microbiol.Rev. 1991; $55: 733$-51.

[10] Peacock SJ, Moore CE, Justice A. Virulent combinations of adhesin and toxi and genes in natural populations of Staphylococcus aureus. Infect Immun. 2002; 70: 4987- 96.

[11] Calderone R, Clancy C. Candida and Candidesia 2nd edition Washington D.C. American Society for Microbiology. 2012. $2^{\text {nd }}$ edition $12-29$.

[12] Nobile CJ, Johnson AD. Candida albicans biofilm and human disease. Annu. Rev. Microbiol. $2015 ; 69: 71$-92. 
[13] Tsui C, Kong EF, Jabra- Rizk MA. Pathogenesis of Candida albicans biofilm Pathog. Dis. 2016; 74 : ftw 018.

[14] Valenza G, Tappe D, Turnwald D, Frosch M, Konig C, Hebestrat H. Prevalence and antimicrobial susceptibility of microorganism isolated from sputa of patients with cystic fibrosis. J. cyst Fibros. 2008; 7: 123 - 127.

[15] Cuesta AI, Jewtuchowicz V, Brusta MI, Nasri MI, Rosa AC. Prevalence of Staphylococcal species and Candida species in the oral cavity and periodontal disease patients. Acta. Odontal. Latinoam. 2010; 23: 20-26.

[16] Koo H, Alban RN, Howlin RR, Stooley P, Hall-Stooley. Targeting microbial biofilms: current and prospective therapeutic strategies. Nat. Rev.Microbiol. 2017; 15: 740 -755.

[17] Achkor JM, Fries BC. Candida infections of the genitourinary tract. Clin. Microbiol. Rev. 2010; $23(2): 253$-73.

[18] Sabel JD, Faro S, Force RW, Faman B, Ledger WJ, Nyinrjesy PR. Vulvovaginal candidiasis ; epidemiologic, diagnostic therapeutic considerations. Am. J. Obstret. Gynecol. 1998; 178(2): 203 -213.

[19] Cheesebrough M. District laboratory Practice in Tropical countries Part 2.Cambridge University Press, USA. 2006; $624-635$.

[20] Donbraye -Emmanuel 00, Okonko IO, Alli JA, Ojezele MO, Nwanze JC. Detection and prevalence of Candida albicans among pregnant women in lbadan. Nigeria. World Applied Science Journal. 2010; 10(9): 986 -991.

[21] Smith AJ, Roberson O, Tang MK, Jackson MS, Mackenzie D, Bagg J. The ecology of Staphylococci in the oral cavity. A review J.Med.Microbiol. 2001; 50: 940 -946.

[22] Nejad BS, Rafiel F, Moosunejad T. Prevalence of Candida species in the oral cavity of patients with periodontitis. African Journal of Biotechnology. 2011; 10(15): 2987 -2990.

[23] Fan SR, Liu XP, Li JW. Clinical characteristics of vulvovaginal candidiasis and antifungal susceptibities of Candida species isolates among patients in Southern China from 2003 to 2006. J.Obstet Gynaecol Res. 2008; 34 (4): 561 -6.

[24] Amouri l, Sellani H, Borji N, Abbe S, Sellani A, Cheikhrouhou F. Epidemiological survey of vulvovaginal Candidosis in Sfax, Tunisia. Mycoses. 2011; 54(5): e499 -505.

[25] Richter SS, Galask RP, Messer SA, Hollis RJ, Diekema DJ, Pfaller MA. Antifungal susceptibilities of Candida species causing vulvovaginitis and epidemiology of recurrent cases.J.Clin. Microbiol. 2005; 43(5): 2155 - 2160.

[26] Adad SJ, De-lima RV, Sawan ZT, Silva ML, De -souza MA, Saldahan JC, Falco VA, Da-cunha AH, Munta EF. Frequency of Trichomonas vaginalis, Candida species and Garderella vaginalis in cervical smears in four different decades. Sao Paolo Med. J. 2001; 119(6): 200 -205.

[27] Alli JAO, Okonko JO, Odu NN, Kolade AF, Nwanze JC. Detection and prevalence of Candida isolates among patients in lbadan Southwestern Nigeria. Journal of Microbiology and Biotechnology Research. 2011; 1(3): 176 -184.

[28] Zeng X, Zhang Y, Xue Y, Xu H, An R. Risk factors of vulvovaginal Candidiasis among women of reproductive age in Xi'an: a cross- sectional study. Biomed Res. lnt. 2018; 9703754 doi.10 : 1155/2018 /9703754.

[29] Sustr V, Foessleitner P, Kiss H, Farr A. Vulvovaginal candidosis, current concepts, challenges and perspectives. J.Fungi. 2020; 6(4): 267.

[30] Ghaddar N, EI-Roz A, Ghssein G, lbrahim JN. Emergence of vulvovaginal candidiasis among Lebanese pregnant women,prevalence, risk factors and species distribution. Infect. Dis .Obstet Gynecol. 2019;5016810 .doi: $10.1155 / 2019 / 501681$. 